\title{
Autoimmune Hepatitis (AIH) in Acquired Immune Deficiency Syndrome (AIDS): A Case Report and Review of Literature
}

\author{
Jordan Roussel, ${ }^{1}$ Sudha Pandit, ${ }^{2}$ Paul Jordan, ${ }^{2}$ Moheb Boktor ${ }^{(D)},{ }^{2}$ Kurt Knowles $\left(\mathbb{D},{ }^{3}\right.$ \\ Nester Dela Cruz, ${ }^{3}$ and Hrishikesh Samant $\mathbb{I D}^{2}$ \\ ${ }^{1}$ Department of Internal Medicine, Louisiana State University Health Sciences Center, Shreveport, LA, USA \\ ${ }^{2}$ Department of Gastroenterology and Hepatology, Louisiana State University Health Sciences Center, Shreveport, LA, USA \\ ${ }^{3}$ Department of Pathology, Louisiana State University Health Sciences Center, Shreveport, LA, USA
}

Correspondence should be addressed to Hrishikesh Samant; samanthrishi@gmail.com

Received 16 February 2019; Revised 22 April 2019; Accepted 2 May 2019; Published 9 June 2019

Academic Editor: Melanie Deutsch

Copyright (C) 2019 Jordan Roussel et al. This is an open access article distributed under the Creative Commons Attribution License, which permits unrestricted use, distribution, and reproduction in any medium, provided the original work is properly cited.

\begin{abstract}
The common causes of abnormal liver chemistries in human immunodeficiency virus (HIV) infected patients are multifactorial. Diagnosis of autoimmune hepatitis (AIH) in HIV infected patients is intriguing but data is scarce. Unmasking of AIH during immune reconstitution in HIV patients after starting antiretroviral therapy is reported but not with advanced acquired immunodeficiency syndrome (AIDS). Here we present a fascinating case of 32-year-old African-American man with advanced AIDS who presented with elevated transaminases. He was diagnosed with AIH before starting antiretroviral therapy and successfully treated with prednisolone and azathioprine with antiretroviral therapy despite very low CD4 count.
\end{abstract}

\section{Introduction}

Patients with human immunodeficiency virus (HIV) infection have a wide variety of causes for elevated liver chemistries. Some common etiologies are coinfections such as hepatitis B (HBV), Hepatitis C (HCV), opportunistic infection, and alcoholic and nonalcoholic fatty liver disease, and less common causes include cholecystitis, AIDS related cholangiopathy, and antiretroviral drug toxicity. Autoimmune hepatitis (AIH) is rarely reported as cause of liver function derangement in HIV patient. The relation between $\mathrm{HIV}$ and $\mathrm{AIH}$ is interesting. The pathophysiology of $\mathrm{AIH}$ begins with loss of self-tolerance of T-lymphocytes causing an overwhelming immune cascade leading to autoantibodies to liver cells [1]. On the other hand, HIV is a disease that causes decreased activity of the immune system by infecting and destroying T-lymphocytes and also sometimes developing various antibodies by polyclonal stimulation of $\mathrm{B}$ cells. The diagnosis of AIDS is made when a patient with an HIV infection becomes significantly immunocompromised with a severely reduced CD4 count. This very low CD4 cells and severely immunocompromised state is the basis of why developing AIH in a patient with AIDS may be extremely rare. AIH with advanced AIDS, to our knowledge, has never been reported. Furthermore, treating AIH with high dose immunosuppressive medication is usually risky in AIDS patient. We herein report the case of advanced AIDS patient who was diagnosed with AIH before starting antiretroviral therapy and successfully achieved remission of transaminitis on standard immunosuppressive therapy for $\mathrm{AIH}$ and antiretroviral therapy without any side effects.

\section{Case Presentation}

Our patient is a 32-year-old African-American male with past medical history of HIV/AIDS, hypertension, and focal segmental glomerulosclerosis (FSGS) related chronic kidney disease stage 3, who presented to our institution complaining of a two-week history of generalized abdominal pain, associated with jaundice, pruritus, nausea, and vomiting. The patient's HIV/AIDS status was significant for a very low CD4 count of 11 cells $/ \mathrm{mm} 3$ with a viral load of $64000 \mathrm{IU} / \mathrm{ml}$. Patient had history of nonadherence to antiretroviral therapy and was not taking his medications since his diagnosis of HIV. Review of systems was otherwise normal. Travel history or use of nonprescription medications was negative. Family history was 


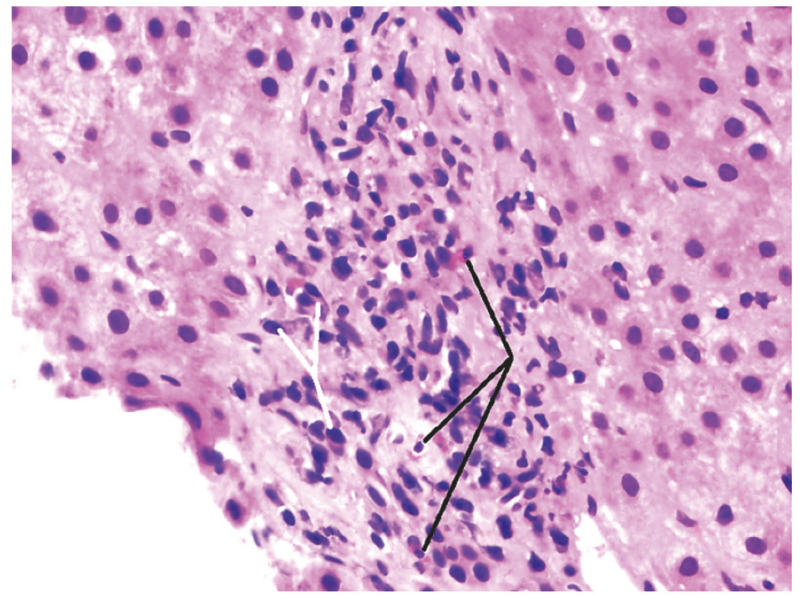

Figure 1: Liver biopsy. The portal triad demonstrates plasma cells (white arrows) and eosinophils (black arrows) consistent with autoimmune hepatitis. H\&E stain, high power (400X).

noncontributory. Surgical history included a knee surgery. He had 20-pack year history of cigarette smoking but denied alcohol, illicit drug use, or hepatotoxic medications. Pertinent positives in the physical examination included icteric sclera, hepatomegaly $2 \mathrm{~cm}$ below costal margin, and jaundiced skin. Admission labs revealed abnormal liver chemistries: aspartate transferase (AST) $255 \mathrm{U} / \mathrm{L}$, alanine transferase (ALT) $461 \mathrm{U} / \mathrm{L}$, alkaline phosphatase $123 \mathrm{U} / \mathrm{L}$, gamma glutamyl transferase $34 \mathrm{U} / \mathrm{L}$, and total bilirubin $17.4 \mathrm{mg} / \mathrm{dL}$. Viral hepatitis workup was negative which included IgM/Total hepatitis A, IgM hepatitis E, anti-HCV antibody, HCV RNA, HEV RNA, hepatitis B surface antigen, IgM/total hepatitis $B$ core antibody, and HBV DNA viral load. Other infectious disease workups including cytomegalovirus (CMV), Herpes Simplex (HSV), Epstein Barr (EBV), syphilis, and varicella were all negative. Ultrasound liver revealed hepatomegaly. MRCP done for borderline elevated alkaline phosphatase and pruritis but was negative for any biliary pathology. Urine drug screen was negative. Amongst autoimmune markers, anti-nuclear antibody (ANA), and liver kidney microsomal (LKM)-1, anti-mitochondrial antibody (AMA) was negative, but anti-smooth muscle antibody (SMA) titers by ELISA came positive at 1:84 with elevated immunoglobulin G levels of $3540 \mathrm{~g} / \mathrm{L}$ (twice upper limit of normal levels). Further evaluation with core liver biopsy revealed chronic lymphoplasmacytic inflammation with abundant plasma cells and minimal interface activity without bile duct damage, necrosis, or fibrosis suggestive of autoimmune hepatitis (Figure 1). Patient fulfilled the Revised Original Score for Autoimmune Hepatitis with score of 20 giving diagnosis as "Definite for AIH" $[16,17]$. The patient was started on standard dose of highly active antiretroviral treatment (HAART) and prednisone $30 \mathrm{mg}$ oral daily with close monitoring of liver enzymes. After starting prednisone, the patient improved symptomatically with improvement in liver functions and immunoglobulin levels. Patients CD4 count remained $<50$ during the period of liver function improvement. Azathioprine was introduced gradually at $1-1.5 \mathrm{mg} / \mathrm{kg}$ on week 2 after confirming normal thiopurine methyltransferase (TPMT) phenotype and subsequently steroid was tapered off successfully. Patient's liver enzymes normalized completely after 9 months with continued azathioprine and HAART.

\section{Discussion}

Autoimmune hepatitis is a rare cause of transaminitis in HIV infected patients with the more common causes being a coinfection such as HBV and HCV due to the same route of transmission as HIV. Also, opportunistic infection, steatohepatitis, and medications toxicity may coexist causing abnormal liver enzymes in HIV population [18]. In recent study by Virot and collogues investigating the prevalence of autoimmune diseases in HIV patients, only one case of AIH was identified in a cohort of 5186 patients [19].

The HIV virus causes the destruction of the host's Tlymphocytes resulting in an immunocompromised state. Once the CD4 T-lymphocytes are less than 200 or the patient develops an AIDS-defining condition, the term acquired immunodeficiency syndrome (AIDS) can be used. Once the CD4 count drops below 50, it is called "advanced AIDS". Since AIH results from overactivation of T-lymphocytes, whereas AIDS is a result of depletion of T-lymphocytes, these contrasting processes may be the reason for the low prevalence of AIH in HIV patients. Although it is uncommon, autoimmune disorders like immune thrombocytopenic purpura, antiphospholipid syndrome, sarcoidosis, SLE, and Graves' disease have been described in HIV [20]. Pathogenesis of AIDS is known to initiate autoimmune phenomenon by polyclonal stimulation of B cells by HIV virus itself and development of hypergammaglobulinemia in proinflammatory milieu. In HIV, immune system is known to attack itself and form circulating autoimmune antibodies [21]. Vergani and collogues showed cross-reaction between anti-liver kidney microsome (LKM)-1 antibodies (involved in type $2 \mathrm{AIH}$ ) against CYP2D6 and HCV, HSV, and CMV [22]. Nowadays more cases of autoimmune diseases in HIV are reported with increasing use of HAART for treatment of HIV, suggesting unmasking of an underlying autoimmune dysfunction with immune reconstitution which predominantly involve CD8 cells $[2,4]$. However, in the present case, at the time of diagnosis of AIH, patient was not taking HAART and had very low $\mathrm{CD} 4$ count without any evidence of coinfection.

We searched PubMed database for relevant English literature with the search terms of "Autoimmune hepatitis" and "human immunodeficiency virus", "Acquired Immunodeficiency syndrome" and identified 14 case reports/series of 35 patients with the concomitant diagnosis of AIH and HIV only without any coinfection (Table 1). In these previous reported cases/series, the range of $\mathrm{CD} 4$ count at the time of AIH diagnosis was between 174 and 1011 cells $/ \mathrm{mm} 3$ with a viral load between undetectable and 27,000 IU/ml [2-15]. Our patient's CD4 count was just 11 cells $/ \mathrm{mm} 3$ and viral load was $64,000 \mathrm{IU} / \mathrm{ml}$ at the time of $\mathrm{AIH}$ diagnosis. Also, cases described in the literature thus far only had HIV infection 


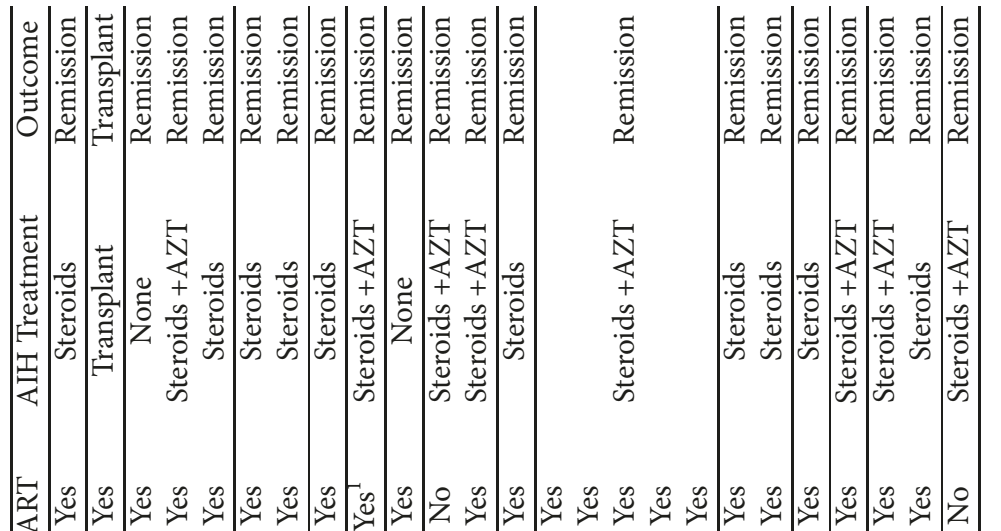

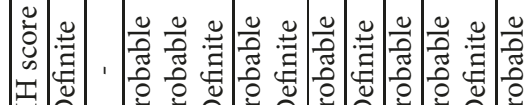

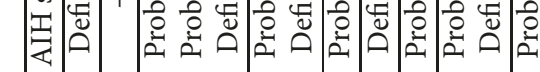

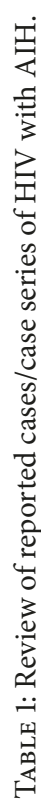

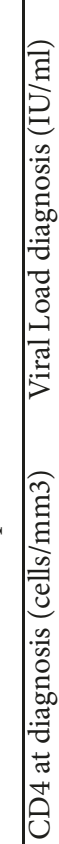

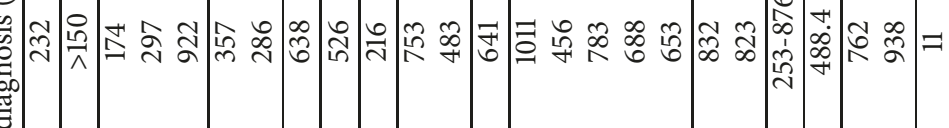

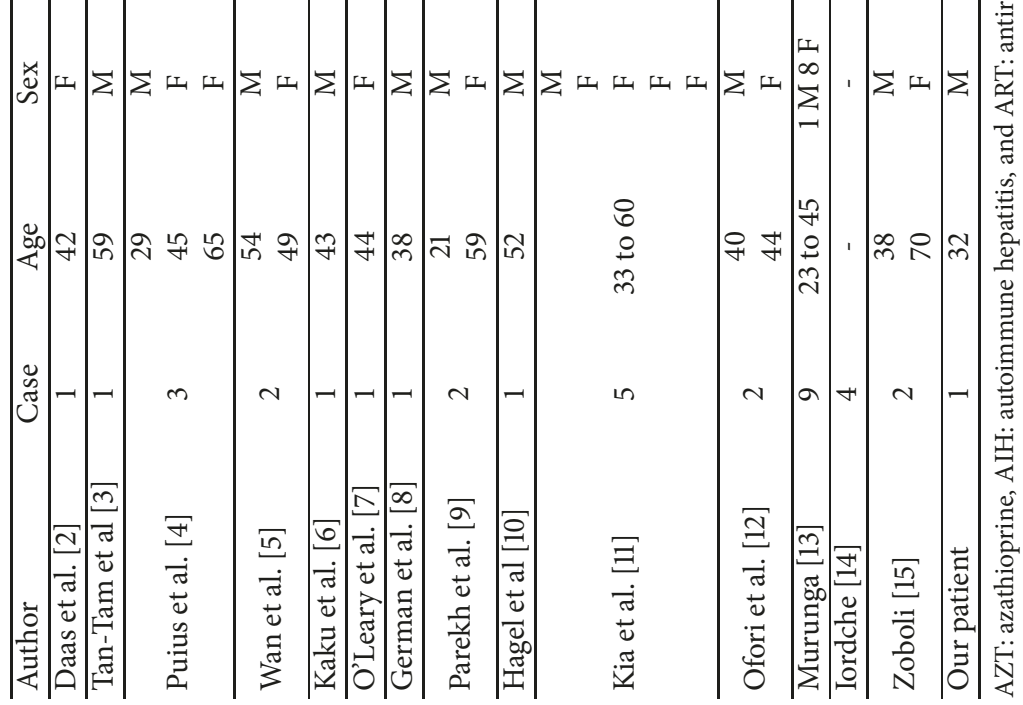


with AIH diagnosis, but our patient is unique in the sense that he had advanced AIDS when he was diagnosed with AIH.

Although there are more common causes of transaminitis in HIV/AIDS patients, an autoimmune hepatitis can still be a possibility. Physicians must be aware of this completely treatable but challenging "AIH in HIV/AIDS" diagnosis which frequently will need detailed biochemical, viral, autoimmune workup, and likely liver biopsy. Furthermore, there are no guidelines in the treatment of $\mathrm{AIH}$ in $\mathrm{HIV}$ patients. Standard immunosuppressive therapy, such as steroids and azathioprine, is usually thought to be high-risk in already immunocompromised HIV patients. There are only two reported cases, where patient's condition improved with HAART alone [3, 7]. Prior retrospective case reports showed that standard AIH therapy was successful in well controlled HIV on HAART (CD4 >250 and undetectable HIV viral load). In our case, despite very low CD4 count and high viral load, the patient showed complete remission of liver functions following the administration of prednisolone and azathioprine for AIH and starting HAART for AIDS.

\section{Conclusion}

Our case highlights that etiological workup for elevated liver chemistry in HIV/AIDS should include autoimmune hepatitis, irrespective of degree of immunosuppression and despite severe immunocompromised state, standard treatment for AIH can be used safely with HAART under close supervision.

\section{Data Availability}

Data sharing is not applicable to this article as no datasets were generated or analyzed during the current study.

\section{Consent}

A written informed consent was obtained from the patient for publication of this case report and accompanying images.

\section{Disclosure}

This study was presented as poster in American College of Gastroenterology (ACG) Conference-Oct 2017.

\section{Conflicts of Interest}

The authors have no conflicts of interest or financial relationships to disclose.

\section{Authors' Contributions}

Jordan Roussel and Sudha Pandit wrote the article and literature review and have equal contribution. Kurt Knowles and Nester Dela Cruz provided the histopathology images. Paul Jordan reviewed the manuscript. Hrishikesh Samant reviewed and edited the manuscript. All authors read and approved the final manuscript.

\section{References}

[1] E. L. Krawitt, "Autoimmune hepatitis," The New England Journal of Medicine, vol. 354, no. 1, pp. 54-66, 2006.

[2] H. Daas, R. Khatib, H. Nasser, F. Kamran, M. Higgins, and L. Saravolatz, "Human immunodeficiency virus infection and autoimmune hepatitis during highly active anti-retroviral treatment: A case report and review of the literature," Journal of Medical Case Reports, vol. 5, p. 233, 2011.

[3] C. Tan-Tam, P. Liao, J. S. Montaner et al., "HIV and liver transplantation: the british columbia experience, 2004 to 2013," Canadian Journal of Infectious Diseases \& Medical Microbiology, vol. 25, Article ID 373898, pp. 159-162, 2014.

[4] Y. A. Puius, L. M. Dove, D. G. Brust, D. P. Shah, and J. H. Lefkowitch, "Three cases of autoimmune hepatitis in HIVinfected patients," Journal of Clinical Gastroenterology, vol. 42, no. 4, pp. 425-429, 2008.

[5] D. W. Wan, K. Marks, R. K. Yantiss, and A. H. Talal, "Autoimmune hepatitis in the hiv-infected patient: A therapeutic dilemma," AIDS Patient Care and STDs, vol. 23, no. 6, pp. 407413, 2009.

[6] Y. Kaku, S. Kodama, M. Higuchi et al., "Corticoid therapy for overlapping syndromes in an HIV-positive patient," Internal Medicine, vol. 54, no. 2, pp. 223-230, 2015.

[7] J. G. O'Leary, K. Zachary, J. Misdraji, and R. T. Chung, "De novo autoimmune hepatitis during immune reconstitution in an HIV-infected patient receiving highly active antiretroviral therapy," Clinical Infectious Diseases, vol. 46, no. 1, pp. e12-e14, 2008.

[8] V. German, A. Vassiloyanakopoulos, D. Sampaziotis, and G. Giannakos, "Autoimmune hepatitis in an HIV infected patient that responded to antiretroviral therapy," Infectious Diseases, vol. 37, no. 2, pp. 148-151, 2005.

[9] S. Parekh, Z. Spiritos, P. Reynolds, S. Parekh, A. Perricone, and B. Quigley, "HIV and autoimmune hepatitis: a case series and literature review," Journal of Biomedical Sciencies, vol. 6, no. 2, 2017.

[10] S. Hagel, T. Bruns, A. Herrmann, A. Tannapfel, and A. Stallmach, "Autoimmune hepatitis in an HIV-infected patient: An intriguing association," International Journal of STD \& AIDS, vol. 23, no. 6, pp. 448-450, 2012.

[11] L. Kia, A. Beattie, and R. M. Green, "Autoimmune hepatitis in patients with human immunodeficiency virus (HIV): Case reports of a rare, but important diagnosis with therapeutic implications," Medicine (United States), vol. 96, no. 7, article no. e6011, 2017.

[12] E. Ofori, D. Ramai, M. A. Ona, and M. Reddy, "Autoimmune hepatitis in the setting of human immunodeficiency virus infection: A case series," World Journal of Hepatology, vol. 9, no. 36, pp. 1367-1371, 2017.

[13] E. Murunga, M. Andersson, and C. V. Rensburg, "Autoimmune hepatitis: a manifestation of immune reconstitution inflammatory syndrome in HIV infected patients?" Scandinavian Journal of Gastroenterology, vol. 51, no. 7, pp. 814-818, 2016.

[14] L. Iordache, O. Launay, O. Bouchaud et al., "Autoimmune diseases in HIV-infected patients: 52 cases and literature review," Autoimmunity Reviews, vol. 13, no. 8, pp. 850-857, 2014.

[15] F. Zoboli, D. Ripamonti, S. V. Benatti, L. Comi, and M. Rizzi, "Autoimmune hepatitis and HIV infection: Two case reports and review of the literature," AIDS, vol. 31, no. 15, pp. 2172-2175, 2017. 
[16] F. Alvarez, "International autoimmune hepatitis group report: review criteria for diagnosis of autoimmune hepatitis," Journal of Hepatology, vol. 31, no. 5, pp. 929-938, 1999.

[17] A. J. Czaja, "Performance parameters of the diagnostic scoring systems for autoimmune hepatitis," Hepatology, vol. 48, no. 5, pp. 1540-1548, 2008.

[18] N. Crum-Cianflone, G. Collins, S. Medina et al., "Prevalence and factors associated with liver test abnormalities among human immunodeficiency virus-infected persons," Clinical Gastroenterology and Hepatology, vol. 8, no. 2, pp. 183-191, 2010.

[19] E. Virot, A. Duclos, L. Adelaide et al., "Autoimmune diseases and HIV infection a cross-sectional study," Medicine (Baltimore), vol. 96, article no. e5769, 2017.

[20] G. Zandman-Goddard and Y. Shoenfeld, "HIV and autoimmunity," Autoimmunity Reviews, vol. 1, no. 6, pp. 392-437, 2002.

[21] R. Root-Bernstein, "Antigenic complementarity between HIV and other AIDS-associated infections results in idiotypeantiidiotype antibody complexes that cross react with lymphocyte proteins," Vaccine, vol. 23, no. 17-18, pp. 2160-2163, 2005.

[22] D. Vergani and G. Mieli-Vergani, "Aetiopathogenesis of autoimmune hepatitis," World Journal of Gastroenterology, vol. 14, no. 21, pp. 3306-3312, 2008. 


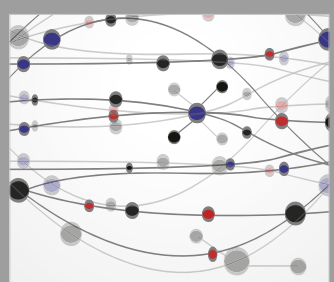

The Scientific World Journal
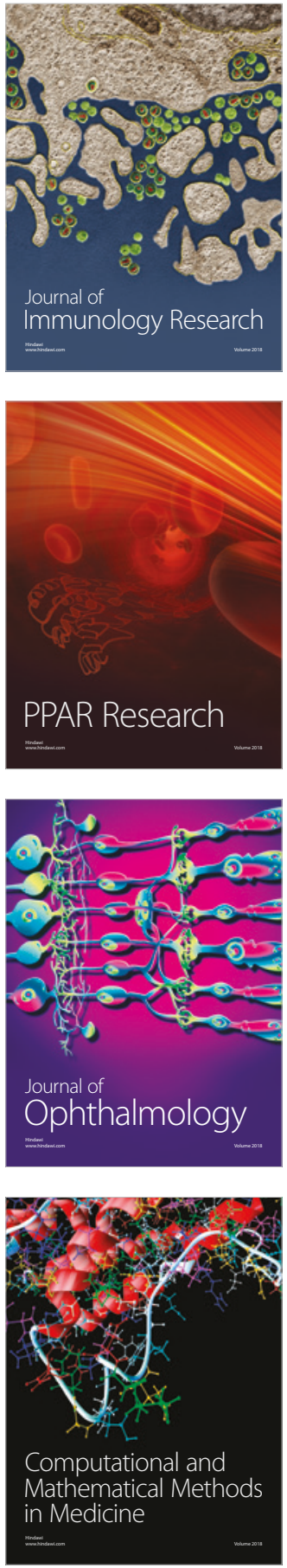

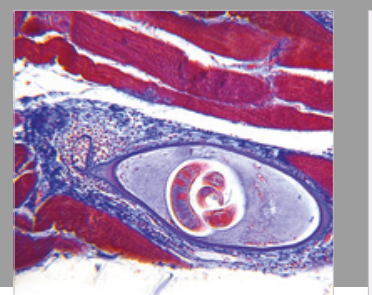

Gastroenterology Research and Practice

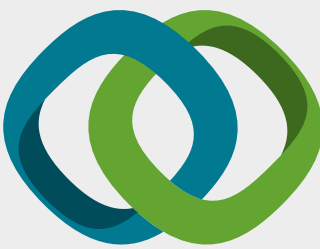

\section{Hindawi}

Submit your manuscripts at

www.hindawi.com
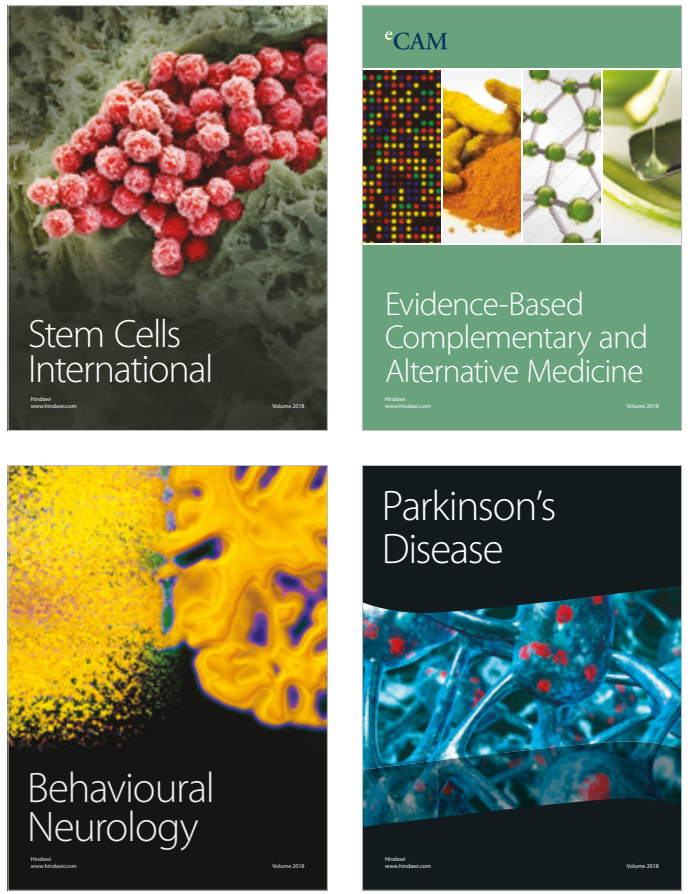

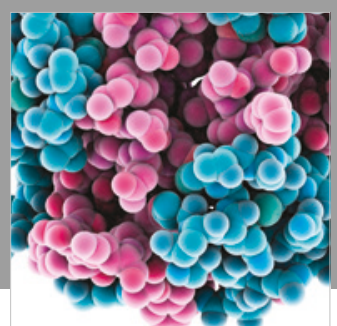

ournal of

Diabetes Research

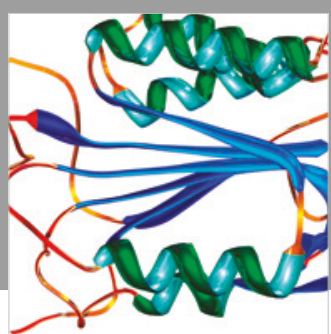

Disease Markers
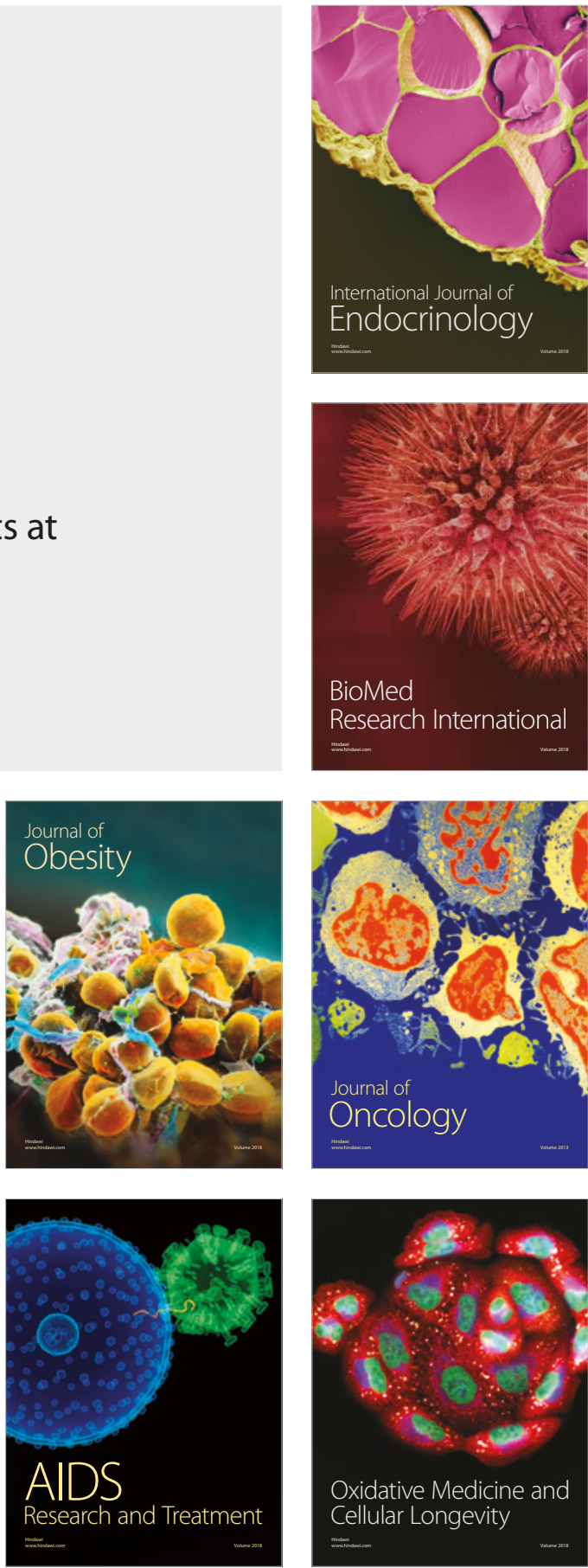